\title{
A GARANTIA FUNDAMENTAL IRRESTRITA DO DIREITO DE ACESSO À JUSTIÇA EM FACE DA PERTINÊNCIA TEMÁTICA NO CONTROLE CONCENTRADO DE CONSTITUCIONALIDADE
}

\author{
Eloy Pereira Lemos Junior ${ }^{1}$ \\ Cristina Atayde Leite ${ }^{2}$
}

\section{Resumo:}

O artigo busca estudar a pertinência temática no controle concentrado de constitucionalidade. Será investigado seu surgimento no ordenamento pátrio e as razões fundamentadoras que alçaram a pertinência temática como um óbice a ser superado por certos entes legitimados quando da utilização processual do controle concentrado de constitucionalidade. A abordagem a que se propõe visa a indagar sobre a (i)legitimidade de tal restrição frente ao direito fundamental do acesso à justiça e do caráter coletivo das ações que se prezam a tutelar direitos transindividuais. Para tanto, utilizar-se-á o método de pesquisa dedutivo, através da técnica bibliográfica.

Palavras-chave: Direito Constitucional. Direitos Fundamentais. Acesso à Justiça. Controle concentrado de constitucionalidade. Ações Coletivas.

\section{THE FUNDAMENTAL GUARANTEE OF THE RIGTH OF ACCESS TO JUSTICE IN FACE THE RELEVANCY THEME IN THE CONCENTRATED MODEL OF JUDICIAL REVIEW}

\begin{abstract}
This article aims to analyzed the 'relevancy theme' in the concentrated model of judicial review. Will be investigate its beginning in the Brazilian's Law and the reasons that have reached the 'relevancy theme' as an impediment to be overcome by certain legitimate entities when concentrated model of judicial review is being used. The proposed approach aims to question about the (il)legitimacy of such restriction in front of the access to the justice and the collective character of its actions that defend the transindividual rights. For that, the deductive research method will be applied through the biographical technique.
\end{abstract}

Keywords: Constitutional right. Fundamental Rights. Access to the Justice. Concentrated model of judicial review. Class Actions.

\section{INTRODUÇÃO}

\footnotetext{
$1 \quad$ Doutor em direito pela UFMG (2007), possui mestrado e especializações. Foi bolsista CAPES (2005) na Universidade de Lisboa, atualmente bolsista FUNDEP-UFMG (desde 2013). Avaliador de cursos de direito pelo INEP-MEC (desde 2010). Atualmente, é professor titular do mestrado e da graduação da Universidade de Itaúna (MG). Advogado.
}

2 Mestranda em Direitos Fundamentais pela Universidade de Itaúna - MG. Advogada. 
O presente ensaio busca investigar a pertinência temática como requisito elaborado jurisprudencialmente pelo Supremo Tribunal Federal em sede de controle concentrado de constitucionalidade. E a questão que se apresenta é como uma restrição jurídica - já que não se amolda nem como condição de ação, ou tampouco como pressuposto processual - possa se consagrar sem o escopo de uma autorização legislativa? Esse instituto se adequa ao modelo coletivo de tutela de interesses transindividuais?

Isso porque o direito do acesso à justiça constitui-se no mais fundamental dos direitos. É por meio dele, que todos os demais direitos podem ser reivindicados, alcançando o mosaico de garantias constitucionais para a sua inserção na realidade vivenciada dos sujeitos. A considerar ainda, nesse quadro, que a ação de controle concentrado de constitucionalidade se apresenta como uma ação coletiva, de interesse público, de modo que o ordenamento jurídico, que se tutela, constitui-se em bem nacional.

E, em que pese o Estado Democrático de Direito apresentar um compromisso com a transformação, com justiça, da realidade social, cujo objetivo se alicerça a República Federativa do Brasil, não parece coadunar, a esse quadro, uma restrição, sem fundamentação normativa, a uma ação de controle constitucional.

Ademais, a nova concepção jurídica caminha no sentido de ampliar a tutela dos direitos transindividuais, de modo a sistematizar os conflitos de massa da sociedade, que se abriu a novas causas e a novos titulares.

Para tanto, no estudo acerca da (i) legitimidade da pertinência temática, o presente trabalho objetiva, primeiramente, abordar algumas considerações sobre o caráter coletivo e indisponível da ação de controle abstrato de constitucionalidade. Em seguida, será investigado o surgimento da pertinência temática como posicionamento erigido pelo Supremo Tribunal Federal a um óbice que necessita ser vencido para o conhecimento da referida ação.

Isto porque, em nome da autoridade da Constituição, uma ação de controle constitucional apresenta-se como relevante instrumento político-jurídico apto a refletir os valores de uma sociedade.

Dessa forma, utilizar-se-á o método de pesquisa dedutivo, aliado à técnica bibliográfica e documental, a fim de buscar nos teóricos a fundamentação pertinente ao tema, apresentada em livros, artigos, periódicos e outros. 


\section{A FEIÇÃO COLETIVA DO CONTROLE ABSTRATO DE CONSTITUCIONALIDADE}

A tutela coletiva, embora já não se apresente como novidade na experiência brasileira, ainda se vê envolta pelo manto de uma concepção individualista, resquício de uma era iluminista onde o individualismo impregnava todo o pensamento filosófico jurídicopolítico do momento, em busca da limitação de poderes do Estado.

Ada Pelegrini Grinover aponta que entre os países da civil Law o Brasil foi o pioneiro na criação e implementação de processos coletivos. Representa, ao final do milênio, uma das conquistas mais expressivas do Direito brasileiro, “[...] carregados de relevância política e capazes de transformar conceitos jurídicos estratificados, os interesses transindividuais tem uma clara dimensão social e configuram uma nova categoria política e jurídica.” (GRINOVER, 1999, p. 1).

Desenvolvidas algumas legislações sobre o tema, ao longo do ordenamento jurídico brasileiro, como a Ação Popular, a Consolidação de Legislação Trabalhista, a Ação Civil Pública, a Lei n. 7.913/89, sobre o ressarcimento de danos aos investidores no mercado imobiliário, considerada como nossa primeira class action for damages, até desaguar no Código de Defesa do Consumidor, tem-se que a Constituição Federal, de 1988, viria a ser o grande trunfo para reforçar e impulsionar a linha evolutiva do processo coletivo.

Nas palavras de Mancuso, a Constituição Federal contribuiu na medida em que:

[...] positivando relevantes valores metaindividuais como o meio ambiente, inclusive o do trabalho; patrimônio cultural, consumidores, política urbana; instaurando uma democracia participativa que busca congregar Estado e Coletividade na defesa da boa gestão da coisa pública; credenciando entidades associativas e sindicatos ao ajuizamento de pleitos coletivos, inclusive mandado de segurança coletiva; autorizando um rol de entes públicos e Autoridades a propor ações no controle direto de constitucionalidade. (MANCUSO, 2007, p. 57).

Da mesma feita, Almeida (2007, p. 33) defende que com a Constituição Federal surge um novo ramo do direito processual, qual seja, o direito processual coletivo. Sua natureza jurídica é de um “[...] de direito processual-constitucional-social [...]”, e o seu método não é apenas um método técnico-jurídico, mas essencialmente pluralista, onde se busca uma proteção potencializada da Constituição e do Estado Democrático de Direito mediante a transformação da realidade social com justiça. 
Em suas palavras:

O direito processual coletivo brasileiro, no plano do seu objeto material, divide-se em especial e comum. O direito processual coletivo especial se destina ao controle concentrado ou abstrato de constitucionalidade [...] e o seu objeto material é a tutela de interesse coletivo objetivo legítimo. Especial porque em sede de controle concentrado ou abstrato de constitucionalidade não há, pelo menos em tese, lide. [...] A finalidade precípua do direito processual coletivo especial é a proteção, em abstrato, de forma potencializada, da Constituição, aqui englobando, especialmente, o Estado Democrático de Direito e os direitos e garantias constitucionais fundamentais. Por outro lado, o direito processual coletivo comum se destina à resolução de conflitos coletivos ou de dimensão coletiva ocorridos no plano da concretude. (ALMEIDA, 2007, p. 31/32).

O que se pretende com tais exposições, é considerar que o ordenamento pátrio proporcionou uma base sólida para uma leitura coletiva de direitos/interesses metaindividuais, que transcendem a esfera individual e repercutem em toda a sociedade. Pelo que, faz-se necessário uma reinterpretação dos instrumentos que manejam uma tutela que se apresenta de caráter eminentemente público e que repercute em amplo espectro.

Nesse sentido, Gomes Junior; Chueiri (2013, p. 463) levantam que a ações coletivas são institutos que não encontram perfeita adequação aos moldes do direito processual civil individual, sendo incorreta a tentativa de enquadrá-las aos conceitos usuais. Faz-se necessária uma adaptação, sem, contudo, perder-se a essência a que se propõe uma tutela coletiva.

Grinover traz uma interessante concepção, defendendo que do reconhecimento e da necessidade de tutela dos interesses transindividuais:

Deles emergiram novas formas de gestão da coisa pública, em que se afirmaram os grupos intermediários. Uma gestão participativa, como instrumento de racionalização de poder, inaugurando um novo tipo de descentralização, não mais limitada ao plano estatal (como descentralização político-administrativa), mas estendida ao plano social, com tarefas atribuídas aos corpos intermediários e às formações sociais, dotados de autonomia e de funções especificas. E isso também significou uma reorganização da sociedade civil em torno de associações e de grupos. (GRINOVER, 1999, p. 1).

Tal corolário ecoa na ação de controle concentrado de constitucionalidade. Instrumentaliza o aval da sociedade em zelar pela ordem constitucional. E bem reflete os valores que tal sociedade gostaria de ver traduzidos em uma normativa.

Barroso (2011, p. 24) esclarece que a proteção dos direitos fundamentais se constitui num dos fundamentos do controle de constitucionalidade, considerando ainda a proteção das 
minorias em face de maiorias parlamentares eventuais. Acentua que "Seu pressuposto é a existência de valores materiais compartilhados pela sociedade que devem se preservados das injunções estritamente políticas".

Concentrando a análise do controle abstrato de constitucionalidade, tem-se que tal instituto fora inserido no Brasil pela Emenda Constitucional n. 16 de 26 de novembro de 1965, complementando o controle difuso de constitucionalidade radicado no ordenamento pátrio já na Constituição Provisória de 1890, art. 58, §1º $a$ e $b$.

Segundo Martins; Mendes (2009, p. 59), a reforma realizada visava imprimir novos rumos à estrutura do Poder Judiciário, que já se deparava com a sobrecarga imposta ao Supremo Tribunal e ao Tribunal de Recursos. Ademais, buscava-se a definição de controvérsias constitucionais nos moldes que afigurasse economia processual às partes e a formação de precedentes que orientaria o julgamento de processos semelhantes.

No mesmo entendimento, Barroso (2011, p. 175) aborda que "O controle judicial de constitucionalidade por via principal ou por ação direta tem como antecedente, embora de alcance limitado, a denominada representação interventiva, criada pela Constituição de 1934." Aduz que, entretanto, fora com a introdução da ação genérica de inconstitucionalidade, pela Emenda Constitucional n.16, de 26 de novembro de 1965, que o controle concentrado por via principal teve seu objeto ampliado, o que acabaria por levá-lo a uma posição de realce dentro do sistema.

Por meio dessa Emenda, pois, o Supremo Tribunal Federal ficava legitimado à apreciação das leis em sede de um controle abstrato, ressaltando-se, que a via de representação era exclusiva do Procurador Geral da República, cargo este de confiança e de livre nomeação e exoneração por ato do Presidente da República.

A Constituição Federal de 1988, entretanto, optou por um modelo de ampla legitimação apta a instrumentalizar o controle de constitucionalidade, a par da nova dogmática de tutela dos direitos e interesses coletivos a qual pretendeu o constituinte realçar.

A extensa lista de legitimados presente no texto constitucional e, por via de consequência, no texto legal fortalece a impressão de que pretendeu o constituinte reforçar o controle abstrato de normas no ordenamento jurídico brasileiro como peculiar instrumento de correção do sistema geral incidente. (MARTINS; MENDES, 2009, p. 151). 
Válida a reconstrução do modelo de inspiração Kelseniano, a fim de destacar o caráter de interesse público que o idealizador do instituto primava como um dos maiores diferenciais entre o modelo norte-americano e o austríaco.

Kelsen (2003, p. 311) aponta que a maior distinção entre as Constituições americana e austríaca diz respeito ao processo pelo qual uma lei é declarada inconstitucional pelo órgão competente. “Assim, em princípio, apenas a violação de um interesse de uma parte pode colocar em movimento o procedimento de revisão judicial da legislação no modelo norteamericano. O interesse na constitucionalidade da legislação, contudo, é um interesse público que não necessariamente coincide com o interesse privado [...]”".

Em nome da 'autoridade da Constituição', nas palavras de Kelsen, o interesse em investigar se uma lei está em conformidade ou não com sua supremacia é um interesse coletivo, e diz respeito a toda sociedade, que, de uma forma ou outra, é afetada pelo julgamento do controle constitucional.

Preceito assentado em nosso ordenamento e ressaltado por Almeida (2007, p. 728) que o objeto do controle concentrado de constitucionalidade "É a tutela concentrada e em abstrato de interesse coletivo objetivo legítimo, [...]".

Não há outro sentido a ser interpretado pela supressão, da Constituição Federal de 1988, do monopólio de ação atribuído ao Procurador-Geral da República e, ao revés, ampliar consideravelmente o rol de legitimados. Pelo seu art. 103, outorga-se o direito de propositura ao Presidente da República, à Mesa do Senado, à Mesa da Câmara dos Deputados, à Mesa da Assembléia Legislativa ou Câmara Legislativa do Distrito Federal, ao Governador de Estado ou do Distrito Federal, ao Procurador-Geral da República, ao Conselho Federal da Ordem dos Advogados, aos Partidos Políticos com representação no Congresso Nacional, às Confederações Sindicais e às Organizações de Classes de âmbito nacional.

Martins; Mendes (2009, p. 156) afirmam que "Essa ampliação da legitimação manifesta claro repúdio a um modelo limitado de direito de propositura. Isto vem explicitado, também, no art. $125, \S 2^{\circ}$, da Constituição,...” autorizando o constituinte estadual a legislar o processo de controle abstrato de constitucionalidade para aferição de leis estaduais e municipais em face da Constituição Estadual.

Percebe-se, com isso, uma feição de abertura do acesso à justiça em contrapartida à limitação de agir que a referida ação padecia. 
Entretanto, a questão da legitimidade nas ações coletivas não se afigura um instituto despido de peculiaridades e questões emblemáticas. Veja-se:

De fato, a busca por um critério seguro para a standing (legitimação para agir) passou a ser a pedra de toque no processo coletivo, justamente porque nesse plano cuida-se de interesses que se diria, dessubstantivados (= indivisíveis e concernentes a sujeitos indeterminados), donde não se revelar viável a técnica que busca estabelecer uma ponte entre uma posição de vantagem adrede definida no ordenamento positivo e um dado sujeito que se afirma titular do valor ou interesse judicializado. Ante essa dificuldade, duas possibilidades então se apresentavam: ou bem se admitia a representação por uma ideological plaintiff (o autor ideológico), assim credenciado por um consentimento dos representados, ou bem esse poder de agir se extrairia a partir da identificação entre os interesses da classe e os do portador judicial. (MANCUSO, 2007, p. 35).

Essa identificação dos interesses da classe e os do portador judicial acabou por se configurar na construção da pertinência temática, o que se verá a seguir.

\section{A PERTINÊNCIA TEMÁtiCA NO CONTROLE CONCENTRAdo DE CONSTITUCIONALIDADE}

O avanço do constituinte de 1988, entretanto, sofreu um entrave jurisprudencial em relação à exigência de uma pertinência temática, ou seja, a demonstração de um interesse específico que conecta os fins institucionais de determinados legitimados à tutela pretendida, pela via de ação de impugnação de uma norma perante a Constituição.

Almeida (2007, p. 762) aborda a questão explicitando que o Supremo Tribunal Federal tem firmado entendimento para que a Mesa da Assembléia Legislativa, os Governadores de Estado e a confederação sindical ou entidade de classe de âmbito nacional demonstrem pertinência temática, uma vez que são considerados autores interessados ou especiais, ao contrário dos demais que são considerados neutros ou universais, e por isso, teriam legitimidade universal. A par disso, estes últimos não precisariam demonstrar pertinência temática.

Buscando os fundamentos de seu surgimento no âmbito do Supremo Tribunal Federal, iniciou-se a investigação pela ADI no 1151-1 MG, Rel. Min. Sepúlveda Pertence:

EMENTA: AÇÃO DIRETA DE INCONSTITUCIONALIDADE LEGITIMAÇÃO - CONFEDERAÇÃO SINDICAL - PERTINENCIA TEMÁTICA. Na ação ajuizada por entidade sindical, perquire-se a 
legitimação considerada a pertinência temática, ou seja, o elo entre os objetivos sociais da confederação e o alcance da norma que se pretenda ver fulminada. Isto não ocorre quando atacado preceito alusivo à anistia e à remissão, visando-se a preservação do erário - artigo $4^{\circ}$ da Lei $\mathrm{n}^{\circ} .11 .508$, de 28 de junho de 1994, do Estado de Minas Gerais. (BRASIL, 1994).

No voto, o Ministro Sepúlveda Pertence noticia que fora consolidado no Tribunal, a partir da ADIn no 305, em 22.5.1991, “[...] a construção do requisito que se denominou de "pertinência temática", condicionante de qualificação das entidades sindicais ou de classe para a propositura da ação direta de inconstitucionalidade”. E ainda faz um levantamento de que uma das primeiras vezes em que o problema fora aventado teria sido pela ADIn 138 (m.c), Lex 146/7, 18. (BRASIL, 1994, p. 9).

Buscando a fonte acima relatada, a ADIn n 138-8 RJ, Rel. Sydney Sanches, sendo pleiteada pela Associação dos Magistrados Brasileiros, realmente traz em seu bojo o debate da questão, que se apresentava controvertida entre os juristas.

EMENTA: AÇÃO DIRETA DE INCONSTITUCIONALIDADE. ENTIDADE DE CLASSE DE ÂMBITO NACIONAL (ART. 103, INC. IX, DA C.F. DE 1988). VICULAÇÃO DE VENCIMENTOS (ART. 37, XIII). ISONOMIA ENTRE AS "CAREIRAS JURIDICAS" (ART. 135). (BRASIL, 1990).

No voto de relator, em sede de medida cautelar, o Ministro Sanches (1990, p. 07) inicialmente reconhece que a Constituição não delimitou o campo de atuação dos legitimados, não cabendo tal conduta ao intérprete. Em suas palavras "Não me parece, pois, em princípio, que o intérprete da Constituição deva, necessariamente restringir tal legitimidade ativa, quando ela não a limitou". E realça que a Constituição pretendeu ampliar o elenco de legitimados à defesa da Constituição Federal. Entretanto, ao longo de sua explanação, enfrenta a dúvida sobre o interesse direto da Associação de Magistrados na vinculação legal de vencimentos de certas carreiras jurídicas, ao teto dos integrantes dos Três Poderes do Estado. Reconhece que a Associação dos Magistrados teria, ao menos, um interesse político no pleito, ao que conclui:

E como a ação direta de inconstitucionalidade não se rege apenas pelos princípios estritamente jurídico-processuais, mas por outros, mais altos, de notório conteúdo político, dada sua própria natureza e finalidade, como tem acentuado esta Corte, em vários precedentes, a legitimidade ativa e o interesse de agir devem ser aferidos por critérios políticos e não estritamente jurídicos e processuais. Alias, não se pode negar a relação de pertinência, entre as finalidades estatutárias da A.M.B e os objetivos perseguidos com a propositura da presente ação. (BRASIL, 1990, p. 11). 
O fato, é que ao final do voto, o Relator acaba vinculando o interesse político da Associação aos seus fins estatutários, mas como uma conotação de alargar a legitimidade da requerente para abranger o tema discutido na ação.

O Ministro Sepúlveda Pertence inicialmente dispõe que o controle abstrato de constitucionalidade é chamado de processo objetivo, sem partes, onde, em princípio, se dispensa a indagação da legitimação ativa dos órgãos autorizados, no interesse impessoal da defesa da Constituição, a provocar a manifestação judicial sobre o pleito. E continua:

Não obstante, Senhor Presidente, também eu, na linha do que acentuou o eminente Ministro Celso de Mello, não afasto, de logo, que se deva exigir uma relação de pertinência entre a finalidade institucional das entidades autorizadas à propositura da ação direta e o objeto concreto desta. (Brasil, 1990, p. 16).

Destaca, entretanto, que essa relação de pertinência não há de se instaurar numa relação subjetiva entre a propositura da ação e o seu objeto, que é o substrato do processo comum. Mas, considerando que o processo objetivo de controle de constitucionalidade se apresenta como um processo onde se exerce a função política do Supremo. Então, por ora, se contenta que a matéria do ato normativo questionada não seja alheia ao âmbito institucional da autora.

O Ministro Paulo Brossard levanta a questão relativa à legitimidade postulatória dos Governadores de Estado em manejar uma ação de controle de constitucionalidade sem demonstração de interesse. Difere, para tanto, a atuação do Presidente da República e do Procurador-Geral da República, por exemplo, porque estes falariam como autoridades nacionais e tem responsabilidade na defesa da ordem constitucional. (BRASIL, 1990, p. 18/19). Sob esse prisma, a questão permite indagar se a legitimação para agir opera em igual intensidade para todos os co-legitimados ativos, o que se apresenta como uma questão em aberto.

No seguimento do julgado, vê-se a passagem de um diálogo que representa a discussão desse ensaio: “O Senhor Ministro Celso Borja: A ordem jurídica pertence a todos, é um bem nacional. O Senhor Ministro Moreira Alves: Mas porque não as associações em geral? Por que não a qualquer brasileiro?” (BRASIL, 1990, p. 22).

É essa perspectiva que se extrai da interpretação de que a Constituição pretendeu ampliar a legitimidade para que sua ordem jurídica se sustentasse nos valores refletidos da 
sociedade. E, na nova feição coletiva da ação, tem-se que a organização dos cidadãos em grupos permite-lhes uma melhor organização, tanto financeira, quanto técnica e ideológica.

Finalizando, o Ministro Moreira Alves vem assentar que:

Em se tratando de processo objetivo, o conceito correspondente ao do interesse subjetivo é o de pertinência objetiva, ou seja, o legitimado para propor a ação direta de inconstitucionalidade tem a sua legitimação circunscrita à pertinência entre suas atribuições e a repercussão nelas da norma que impugna como inconstitucional. (BRASIL, 1990, p. 30).

Válida a referência do julgado na ADI no 1.157-0 DF, Rel. Min. Celso de Mello, requerida pela Confederação dos Servidores Públicos do Brasil e julgada em 01.12.1994, na qual se espraiou o conceito de pertinência temática:

EMENTA: AÇÃO DIRETA DE INCONSTITUCIONALIDADE CONFEDERACAO DOS SERVIDORES PUBLICOS DO BRASIL AUSENCIA DE LEGITIMIDADE ATIVA “AD CAUSAM" POR FALTA DE PERTINENCIA TEMÁTICA - INSUFICIENCIA, PARA TAL EFEITO, DA MERA EXISTÊNCIA DE INTERESSE DE CARATER ECONOMICO-FINANCEIRO - HIPOTESE DE INCOGNOSCIBILIDADE - AÇÃO DIRETA NÃO CONHECIDA. O requisito da pertinência temática - que se traduz na relação de congruência que necessariamente deve existir entre os objetivos estatutários ou as finalidades institucionais da entidade autora e o conteúdo material da norma questionada em sede de controle abstrato - foi erigido à condição de pressuposto qualificador da própria legitimidade ativa "ad causam" para efeito de instauração do processo objetivo de fiscalização concentrada de constitucionalidade. Precedentes. (BRASIL, 2006).

E o entendimento sobre pertinência temática seguiu-se pelos julgados do Supremo, a rigor da ADI 4912/MG, Relator Min. Edson Fachin, requerida pela Associação dos Oficiais Militares Estaduais do Brasil - AMEBRASIL e Outro, julgada em 11.05.2016:

EMENTA: AÇÃO DIRETA DE INCONSTITUCIONALIDADE. ARTIGOS $8^{\circ}, 9^{\circ}$ E 10 DA LEI COMPLEMENTAR ESTADUAL 125/2012, DE MINAS GERAIS. LEGITIMIDADE ATIVA DAS ENTIDADES DE CLASSE. ALEGAÇÃO DE VIOLAÇÃO AOS ARTIGOS $42, \S \S 1^{\circ} \mathrm{E} 2^{\circ}$, E $142, \S 3^{\circ}, X$, DA CONSTITUIÇÃO FEDERAL. EXIGÊNCIA DE LEI ESTADUAL ESPECÍFICA. COMPETÊNCIA DA UNIÃO PARA O ESTABELECIMENTO DE NORMAS GERAIS. ARTIGO 22, XXI E XXIII. 1. A jurisprudência do Supremo Tribunal Federal estabelece os seguintes requisitos a serem atendidos pelas entidades de classe no ajuizamento de ação de controle concentrado: a) abrangência nacional; b) delimitação subjetiva da associação; c) pertinência temática; e d) compatibilidade entre a abrangência da representação da associação e o ato questionado. Requisitos atendidos pelas associações postulantes. Legitimidade ativa reconhecida [...] (BRASIL, 2016). 
Ainda, ADI 4815 DF, Relatoria da Ministra Cármen Lúcia, requerida pela Associação Nacional dos Editores de Livros - ANEL e julgada em 10.06.2015:

EMENTA: AÇÃO DIRETA DE INCONSTITUCIONALIDADE. ARTS. 20 E 21 DA LEI N. 10.406/2002 (CÓDIGO CIVIL). PRELIMINAR DE ILEGITIMIDADE ATIVA REJEITADA. REQUISITOS LEGAIS OBSERVADOS. MÉRITO: APARENTE CONFLITO ENTRE PRINCÍPIOS CONSTITUCIONAIS: LIBERDADE DE EXPRESSÃO, DE INFORMAÇÃO, ARTÍSTICA E CULTURAL, INDEPENDENTE DE CENSURA OU AUTORIZAÇÃO PRÉVIA (ART. $5^{\circ}$ INCS. IV, IX, XIV; $\left.220, \S \S 1^{\circ} \mathrm{E} 2^{\circ}\right)$ E INVIOLABILIDADE DA INTIMIDADE, VIDA PRIVADA, HONRA E IMAGEM DAS PESSOAS (ART. 5', INC. X). ADOÇÃO DE CRITÉRIO DA PONDERAÇÃO PARA INTERPRETAÇÃO DE PRINCÍPIO CONSTITUCIONAL. PROIBIÇÃO DE CENSURA (ESTATAL OU PARTICULAR). GARANTIA CONSTITUCIONAL DE INDENIZAÇÃO E DE DIREITO DE RESPOSTA. AÇÃO DIRETA JULGADA PROCEDENTE PARA DAR INTERPRETAÇÃO CONFORME À CONSTITUIÇÃO AOS ARTS. 20 E 21 DO CÓDIGO CIVIL, SEM REDUÇÃO DE TEXTO. 1. A Associação Nacional dos Editores de Livros Anel congrega a classe dos editores, considerados, para fins estatutários, a pessoa natural ou jurídica à qual se atribui o direito de reprodução de obra literária, artística ou científica, podendo publicá-la e divulgá-la. A correlação entre o conteúdo da norma impugnada e os objetivos da Autora preenche o requisito de pertinência temática e a presença de seus associados em nove Estados da Federação comprova sua representação nacional, nos termos da jurisprudência deste Supremo Tribunal. Preliminar de ilegitimidade ativa rejeitada. (BRASIL, 2015).

E ADI 4628 DF, Relatoria do Min. Luiz Fux, Requerida pela Confederação Nacional do Comércio de Bens e Turismo - CNC, e julgada em 17.09.2014:

Ementa: CONSTITUCIONAL E TRIBUTÁRIO. IMPOSTO SOBRE OPERAÇÕES DE CIRCULAÇÃO DE MERCADORIAS E DE PRESTAÇÃO DE SERVIÇOS DE COMUNICAÇÃO E DE TRANSPORTE INTERESTADUAL E INTERMUNICIPAL (ICMS). PRELIMINAR. PERTINÊNCIA TEMÁTICA.PRESENÇA DE RELAÇÃO LÓGICA ENTRE OS FINS INSTITUCIONAIS DAS REQUERENTES E A QUESTÃO DE FUNDO VERSADA NOS AUTOS. PROTOCOLO ICMS $\mathrm{N}^{\circ}$ 21/2011. ATO NORMATIVO DOTADO DE GENERALIDADE, ABSTRAÇÃO E AUTONOMIA. MÉRITO. COBRANÇA NAS OPERAÇÕ̃ES INTERESTADUAIS PELO ESTADO DE DESTINO NAS HIPÓTESES EM QUE OS CONSUMIDORES FINAIS NÃO SE AFIGUREM COMO CONTRIBUINTES DO TRIBUTO. INCONSTITUCIONALIDADE. HIPÓTESE DE BITRIBUTAÇÃO (CRFB/88, ART. 155, § $2^{\circ}$, VII, B). OFENSA AO PRINCÍPIO DO NÃO CONFISCO (CRFB/88, ART. 150, IV). ULTRAJE À LIBERDADE DE TRÁFEGO DE BENS E PESSOAS (CRFB/88, ART. 150, V). VEDAÇÃO À COGNOMINADA GUERRA FISCAL (CRFB/88, ART. 155, § 20, VI). AÇÃO DIRETA DE INCONSTITUCIONALIDADE JULGADA PROCEDENTE. MODULAÇÃO DOS EFEITOS A PARTIR DO 
DEFERIMENTO DA CONCESSÃO DA MEDIDA LIMINAR, RESSALVADAS AS AÇÕES JÁ AJUIZADAS. 1. A Confederação Nacional do Comércio - CNC e a Confederação Nacional da Indústria - CNI, à luz dos seus fins institucionais, são partes legítimas para a propositura da ação direta de inconstitucionalidade que impugna o Protocolo ICMS n ${ }^{\circ} 21$, ex vi do art. 103, IX, da Lei Fundamental de 1988, posto representarem, em âmbito nacional, os direitos e interesses de seus associados. 2. A modificação da sistemática jurídico-constitucional relativa ao ICMS, inaugurando novo regime incidente sobre a esfera jurídica dos integrantes das classes representadas nacionalmente pelas entidades arguentes, faz exsurgir a relação lógica entre os fins institucionais a que se destinam a CNC/CNI e a questão de fundo versada no Protocolo adversado e a fortiori a denominada pertinência temática (Precedentes: ADI 4.364/SC, Plenário, Rel. Min. Dias Toffoli, DJ.: 16.05.2011; ADI 4.033/DF, Plenário, Rel. Min. Joaquim Barbosa, DJ.: 07.02.2011; ADI 1.918/ES-MC, Plenário, Rel. Min. Maurício Corrêa, DJ.: 19.02.1999; ADI 1.003-DF, Plenário, Rel. Min. Celso de Mello, DJ.: 10.09.1999; ADI-MC 1.332/RJ, Plenário, Rel. Min. Sydney Sanches, DJ.: 06.12.1995). (BRASIL, 2014).

Perceba-se, nos primeiros discursos reportado nos votos contidos nas ADIns supra referidas, uma linha de pensamento processualista nos moldes do processo civil individual, quando, para tanto, buscava-se um interesse de agir da Associação de Magistrados, bem como perquiria-se a respeito dos demais legitimados constitucionais. Imagine-se, por certo, que à época, a dimensão dos direitos metaindividuais ainda não havia ganhado corpo.

Segundo Carvalho, a Constituição pátria elegeu o direito de representação coletiva como corolário da garantia ampla de acesso à justiça de forma a assegurar a devida tutela dos direitos transindividuais. Em suas palavras:

[...] promovendo um corte subjetivo, antes tido quase como absolutamente inadmissível, entre o titular do direito material e o titular do direito de ação, abrindo caminho, assim, para que determinados entes, dotados de representatividade adequada, pudessem comparecer em juízo para a defesa de direito de outrem, com a finalidade de tutelar adequadamente não só os direitos transindividuais, mas também certos direitos individuais. (CARVALHO, 2010, p. 51).

Mas mesmo no âmbito do Supremo, há os que defendem posicionamento diferenciado, como o Ministro Gilmar Mendes. Segundo o autor Mendes (2009, p. 87), parece que a introdução, no sistema de controle abstrato de normas, de ampla legitimação de outorga do direito de propositura a diferentes órgãos da sociedade, pelo constituinte, teve a pretensão de reforçar o controle abstrato de normas como peculiar instrumento de correção do sistema geral incidente. E acrescenta: 
O número limitado de requerentes, os objetivos e a conformação do processo do controle abstrato parecem dispensar a demonstração do interesse jurídico específico do autor como pressuposto de admissibilidade do controle de normas. (MENDES, 2009, p. 112).

Afirma, conforme proposta deste artigo, que o processo de controle abstrato de constitucionalidade fundamenta-se na segurança jurídica e deve ser instaurado no interesse de toda a comunidade.

A teor da proposta Kelseniana, Mendes (2009, p. 114) traz que "A admissibilidade de processo de controle abstrato de normas está apenas vinculada a um interesse público de esclarecimento ou a uma necessidade pública de controle.” De outra forma, não será possível ao controle de constitucionalidade cumprir seu mister.

Diante do que, a falta de regulamentação constitucional, ou mesmo infraconstitucional, delineando limitações ao direito de propositura de ações que pretendam questionar a legitimidade da ordem jurídica perante a Lei Maior, levanta a indagação sobre a correta posição do STF. Posição esta que se apresenta como uma restrição ao direito de acesso à justiça. Ressalte-se que a pertinência chegou a ser regulamentada, no parágrafo único do art. $2^{\circ}$ da Lei n. 9868/1999, mas fora vetada. In verbis: “As entidades referidas no inciso IX, inclusive as federações sindicais de âmbito nacional, deverão demonstrar que a pretensão por elas deduzida tem pertinência direta com os seus objetivos institucionais." (BRASIL, 1999).

Nesse caminho, Cappelletti (1993, p. 21-22) desenvolve os limites de atuação de juízes e legisladores frente ao trabalho criativo do Direito. Reconhecendo que não existe um limite claro entre a interpretação e a criação do direito, apresenta, contudo, um óbice à afirmação de total liberdade do intérprete. Em suas lições:

Discricionariedade não quer dizer necessariamente arbitrariedade, e o juiz, embora inevitavelmente criador do direito, não é necessariamente um criador completamente livre de vínculos. $\mathrm{Na}$ verdade, todo sistema jurídico civilizado procurou estabelecer e aplicar certos limites à liberdade judicial [...] (CAPPELLETTI, 1993, p. 21-22).

Em nosso ordenamento, cujo manto se acoberta pela Constituição, extrai-se dela mesma os limites de atuação. De forma que, irônico que o instrumento que o constituinte elegeu para defesa da própria ordem constitucional seja ele próprio avesso às regras constitucionais.

“A relação de pertinência assemelha-se muito ao estabelecimento de uma condição de ação - análoga, talvez, ao interesse de agir -, que não decorre dos expressos termos da 
Constituição e parece ser estranha à natureza do processo de controle de normas” (MENDES, 2009, p. 174).

Da mesma feita, Cléve (2013, p. 06) sustenta a crítica de que uma restrição deveria decorrer da vontade expressa do Legislador (Constituinte ou infraconstitucional) e não de entendimento jurisprudencial. E ainda, esclarece que a demonstração da adequação temática entre as finalidades estatutárias e o conteúdo da norma impugnada não pode chegar ao ponto de transformar a ação direta em processo subjetivo de tutela de interesse concreto.

Ressalte-se, nas palavras de Dinamarco (2009, p. 322) “A universalidade da tutela jurisdicional constitui acentuadíssima tendência generosa da atualidade e está presente nas preocupações e nos movimentos dos processualistas mais modernos." Com uma visão instrumentalista, o autor aduz que "O acesso à justiça é, mais do que ingresso no processo e aos meios que ele oferece, modo de buscar eficientemente, na medida da razão de cada um, situações e bens da vida que por outro caminho não se poderiam obter.” (Op. Cit., 2009, p. 334).

Impende, pelo exposto, adequar a realidade das ações coletivas ao controle concentrado de constitucionalidade que espelha uma tutela coletiva, qual seja, a autoridade da Constituição, traduzida em um bem nacional.

Cruz; Costa (2016, p. 318) concluem por uma revolução da função da ação judicial. "Que ela não seja apenas um meio de consecução de direitos subjetivos, mas um verdadeiro canal de comunicação entre as reivindicações e os anseios da comunidade, mesmo que tais aspirações não se encaixem no conceito de direito subjetivos".

\section{CONSIDERAÇÕES FINAIS}

O acesso à justiça é um direito e uma garantia fundamental, figurando-se como uma pedra angular entre os Três Poderes, na medida em que também se constitui como mecanismo democrático de participação cidadã.

Sob esses moldes, inerente uma releitura processual, no atual contexto, de uma sociedade massificada e imbuída de conflitos de alcance geral, em que pese a dificuldade de conversão de interesses na busca de uma solução coletiva de conflitos dos direitos fundamentais. Desta feita, a organização da sociedade em grupos potencializa o aprimoramento financeiro, técnico e ideológico na tutela de seus direitos. 
Pelo que, não se afigura que uma interpretação restritiva seja uma posição pautada no ordenamento pretendido pelo constituinte de 1988. A contrario sensu, a ampliação do rol de legitimados ao manejo da ação de controle de constitucionalidade, de forma a abarcar diferentes setores da sociedade, induzem a uma posição oposta.

Conforme demonstrado, a introdução da pertinência temática se apresentara em um momento recente da Constituição. Embora o controle concentrado de constitucionalidade já estivesse no ordenamento desde 1965, fazia-se necessário uma repaginação do instituto, principalmente, em função dos novos atores que o constituinte de 1988 abrangera.

Destaca-se, para tanto, que o controle concentrado de normas se conduz sob os auspícios do interesse público, a rigor da construção Kelseniana. Interesse este indisponível e indispensável para assegurar o primado da autoridade da Constituição.

Sendo a legitimidade de um ordenamento jurídico um bem de todos, como conciliar tal definição em face da necessidade de se demonstrar que o interesse defendido precisaria se coadunar com os fins institucionais de uma entidade de classe? Ressalte-se, que, elevado a texto constitucional, tem-se que a família será tutelada com especial proteção do Estado e da Sociedade. E o meio-ambiente, da mesma feita, se erige como bem coletivo, que materializa direitos subjetivos inclusive da geração vindoura. Segue ainda, o direito a educação, cultura, saúde, e inclusive, na ordem econômica e financeira, encontram-se princípios que dizem respeito a todos. De outra forma dita, se tais bens constituem-se em um direito coletivo, qualquer pessoa tem legitimidade e interesse constitucional de pleitear sua defesa.

Agregando-se à consideração de que um dos objetivos do Estado Brasileiro é promover o bem de todos, conclui-se que qualquer dos legitimados, em sede de controle concentrado de constitucionalidade, estaria apto e constitucionalmente fundamentado a defender os direitos/interesses metaindividuais que estejam sendo abarcados em determinada ação. Tais direitos alteraram o quadro de acesso à Justiça. E a organização da sociedade em grupos representa essa nova face do desenvolvimento das tutelas coletivas, não merecendo a guarida de contenção, senão, a de descerramento.

Não se afigura que o requisito da pertinência seja legítimo frente ao ordenamento jurídico e igualmente não parece se coadunar com o caráter coletivo da referida ação. Ipso facto, a construção jurisprudencial da pertinência temática, como óbice instrumental a ser transposto quando do manejo da ação de controle concentrado de constitucionalidade, sem 
previsão legislativa para tanto, necessita ser revisto à luz do novo modelo Constitucional de tutela coletiva.

\section{REFERÊNCIAS BIBLIOGRÁFICAS}

ALMEIDA, Gregório Assagra de. Direito Material Coletivo: superação da summa divisio direito público e direito privado por uma nova summa divisio constitucionalizada. Belo Horizonte: Del Rey, 2008.

. Manual das Ações Constitucionais. Belo Horizonte: Del Rey, 2007.

$\overline{\operatorname{Rey}, 2007 .}$

. Codificação do Direito Processual Coletivo Brasileiro. Belo Horizonte: Del

Teoria Crítica do Direito e o Acesso à Justiça Como Novo Método de Pensamento.

In: Direitos Fundamentais e Sua Proteção Nos Planos Interno e Internacional. SALIBA, Aziz Tuffi; GOMES JUNIOR, Luiz Manoel; ALMEIDA, Gregório Assagra de. (Orgs.). (Coleção Direitos Individuais e Coletivos, v. 1). Belo Horizonte: Arraes Editores, p. 159-177, 2010.

ALVIN, Eduardo Arruda. Apontamento sobre Processo das Ações Coletivas. In: Processo Civil Coletivo. MAZZEI, Rodrigo; NOLASCO, Rita Dias (Coords.). São Paulo: Quartier Latin, p. 27-64, 2005.

BARROSO, Luis Roberto. O Controle de Constitucionalidade no Direito Brasileiro: exposição sistemática da doutrina e análise da jurisprudência. 5 ed. rev. atual. São Paulo: Saraiva, 2011.

Neoconstitucionalismo e Constitucionalização do Direito (O triunfo tardio do direito constitucional no Brasil). Revista de Direito Administrativo, Rio de Janeiro, v. 240, p. 1-42, jan., 2015.

BRASIL. Supremo Tribunal Federal. Ação Direta de Inconstitucionalidade no 1151-1 MG, Rel. Min. Sepúlveda Pertence, Tribunal Pleno, Requerente: Confederação dos Servidores Públicos do Brasil; Requerido: Governador do Estado de MG; Assembléia Legislativa de MG, Julgamento: 11.11.1994, D.J 19.05.1995.

Ação Direta de Inconstitucionalidade n 138-8 RJ, Rel. Sydney Sanches, Tribunal Pleno, Requerente: Associação dos Magistrados Brasileiros; Requerido: Assembléia Legislativa do RJ, Julgamento: 14.2.1990, D.J 16.11.1990.

Ação Direta de Inconstitucionalidade n¹.157-0 DF, Rel. Min. Celso de Mello, Tribunal Pleno, Requerente: Confederação dos Servidores Públicos do Brasil; Requerido: Governador do Estado de MG; Assembléia Legislativa de MG, Julgamento: 01.12.1994, D.J 17.11.2006. 
Ação Direta de Inconstitucionalidade n.4912-MG, Rel. Min. Edson Fachin, Tribunal Pleno, Requerente: Associação dos Oficiais Militares Estaduais do Brasil AMEBRASIL e Outro; Requerido: Governador do Estado de MG; Assembleia Legislativa de MG, Julgamento: 11.05.2016, D.J 24.05.2016.

Ação Direta de Inconstitucionalidade n.4815-DF, Rel. Min. Cármen Lúcia, Tribunal Pleno, Requerente: Associação Nacional dos Editores de Livros - ANEL; Requerido: Presidente da República; Presidente do Congresso Nacional, Julgamento: 10.06.2015, D.J 01.02.2016.

Ação Direta de Inconstitucionalidade n.4628-DF, Rel. Min. Luiz Fux, Tribunal Pleno, Requerente: Confederação Nacional do Comércio de Bens Serviços e Turismo - CNC; Requerido: Estado do Acre e Outros, Julgamento: 17.09.2014, D.J 24.11.2014.

CAPPELLETTI, Mauro. O Controle Judicial de Constitucionalidade das Leis no Direito Comparado. Tradução: Aroldo Plínio Gonçalves. Revisão: José Carlos Barbosa Moreira. 2. ed. Porto Alegre: S. A. Fabris Editor, 1992.

Juízes Legisladores? Tradução: Carlos Alberto Álvaro de Oliveira, Porto Alegre: S.A. Fabris Editor, 1993.

. GARTH, Bryant. Acesso à Justiça. Tradução: Ellen Gracie Northfleet. Porto Alegre: S. A. Fabris Editor, reimpressão, 2015.

CARVALHO, Acelino Rodrigues. A Natureza da Legitimidade para Agir no Sistema Único de Tutelas Coletivas: uma questão paradigmática. In: Em Defesa de um Novo Sistema de Processos Coletivos: Estudos em Homenagem a Ada Pellegrini Grinover. (Coords.) Maria Clara Gozzoli; Mirna Cianci; Petronio Calmon; Rita Quartieri. São Paulo: Saraiva, p. 25-65, 2010.

CINTRA, Antonio Carlos de Araújo; et.al. Teoria Geral do Processo. 28 ed. São Paulo: Malheiros Editores, 2012.

CLÈVE, Clèrmeson Merlin. Associação e Controle Abstrato de Normas - Não satisfação dos pressupostos da legitimação especial. In: Revista dos Tribunais. v. 938, p. 213, dez., 2013.

CRUZ, Luana Pedrosa de Figueiredo; COSTA, Naony Sousa. Interesse Processual: anotações conceituais, revisitação de um instituto no CPC 2015 e reflexos nas ações coletivas. In:

Revista de Processo RePro. WAMBIER, Teresa Arruda Alvin (Coord.) ano 41, v. 255, maio, p. 309-329, 2016.

DIDIER JR., Fredie. Conceito de Processo Jurisdicional Coletivo. In: Processos Coletivos, v. 7, n. 3, julho/setembro, 2016. Disponível em: < http://www.processoscoletivos.net/revistaeletronica/63-volume-4-numero-3-trimestre-01-07-2014-a-30-09-2014/1458-conceito-deprocesso-jurisdicional-coletivo >. Acesso em 24 Ago. 2016.

DINAMARCO, Cândido Rangel. A Instrumentalidade do Processo. 14 ed. São Paulo: Malheiros Editores, 2009. 
GOMES JUNIOR, Luiz Manoel; CHUEIRI, Miriam Fecchio. Sistema Coletivo: porque não há substituição processual nas ações coletivas. In: Revista de Processo. v. 221, jul., p. 461472, 2013.

GRINOVER, Ada Pellegrini. O Controle de Políticas Públicas pelo Poder Judiciário. In: Direitos Fundamentais e Sua Proteção Nos Planos Interno e Internacional. SALIBA, Aziz Tuffi; GOMES JUNIOR, Luiz Manoel; ALMEIDA, Gregório Assagra de. (Orgs.). (Coleção Direitos Individuais e Coletivos, v. 1). Belo Horizonte: Arraes Editores, p. 1-20, 2010.

Direito Processual Coletivo. In: Pro Justiça. Disponível em:

<http://www.projustica.com.br/viewcontent.php?m=mainlist\&cod=80 >. Acesso em 24 ago. 2016.

A Ação Civil Pública Refém do Autoritarismo. In: Revista de Processo. v. 96, p. 28-36, out/dez., 1999.

HANS, Kelsen. Jurisdição Constitucional. Tradução: Alexandre Krug. São Paulo: Martins Fontes, 2003.

MANCUSO, Rodolfo de Camargo. Jurisdição Coletiva e Coisa Julgada: teoria geral das ações coletivas, 2 ed.rev.atual.ampl. São Paulo: Editora Revista dos Tribunais, 2007.

MARTINS, Ives Gandra da Silva; MENDES, Gilmar Ferreira. Controle Concentrado de Constitucionalidade: comentários à Lei n. 9.868, de 10-11-1999. 3 ed. São Paulo: Saraiva, 2009.

MENDES, Gilmar Ferreira. Jurisdição Constitucional: o controle abstrato de normas no Brasil e na Alemanha. 5 ed. São Paulo: Saraiva, 2009.

NERY JR., Nelson. O Ministério Público e sua Legitimação para a Defesa do Consumidor em Juízo. In: Justitia. n. 55 (160), out/dez., 1992.

SHIMURA, Sérgio. O Papel da Associação na Ação Civil Pública. In: MAZZEI, Rodrigo; NOLASCO, Rita Dias (Coords.). Processo Civil Coletivo. São Paulo: Quartier Latin, p. 141$170,2005$.

STREK, Lênio Luiz. Jurisdição Constitucional e Hermenêutica: perspectivas e possibilidades de concretização dos direitos fundamentais sociais no Brasil. In: Novos Estudos Jurídicos. vol. 8, n. 2, maio/ago., 2003.

; MENDES, Gilmar Ferreira. Comentários ao artigo 103 da Constituição. In: CANOTILHO, José Joaquim Gomes; MENDES, Gilmar F; SARLET, Ingo W; STRECK, Lênio Luiz. (coords.). Comentários à Constituição do Brasil. São Paulo: Saraiva, 2013. 
WAMBIER, Teresa Arruda Alvim. Litispendência em Ações Coletivas. In: Processo Civil Coletivo. MAZZEI, Rodrigo; NOLASCO, Rita Dias (Coords). São Paulo: Quartier Latin, p. 279-295, 2005. 